\title{
The impact of Caesarean delivery mode towards brain and neurodevelopment among children
}

Received 25th August 2020, Accepted $15^{\text {th }}$ September 2020

Link to DOI:

10.25220/WNJ.V04.S2.0005

Journal Website:

www.worldnutrijournal.org
Tjhin Wiguna ${ }^{1}$, Levina Chandra Khoe ${ }^{2}$

1. Department of Psychiatry, Medical Faculty, Universitas Indonesia-Cipto Mangunkusumo General Hospital, Jakarta, Indonesia

2. Department of Community Medicine, Medical Faculty, Universitas Indonesia

\begin{abstract}
In regards to the rising rate of Caesarean birth globally, there is concern about the risk of Caesarean birth in children. However, the effect of Caesarean delivery towards the child brain and neurodevelopment is not well understood. We reviewed articles from online database with topics related to the relation between Caesarean delivery mode and brain development or neurodevelopment or behavior and emotional development. Several studies discussed how birth mode could affect brain structural connectivity through neural and hormone changes. Some studies also assessed possible effect on child's psychological development. The result showed differences in child's brain development between caesarean and natural delivery in the early life, but not in the long run. Additionally, there was no significant association between birth mode and emotional problem.
\end{abstract}

Keywords: Caesarean section, children, brain development, neurodevelopment, behavior and emotional

\section{Introduction}

In general, birth delivery can be divided into three categories: natural unassisted delivery, assisted delivery, and caesarean delivery. It is commonly known that Caesarean section (C-section) holds important role in saving lives of mothers and infants under certain medical conditions, e.g. labor dystocia, fetal malpresentation, fetal distress, etc. Therefore, the use of C-section for birth delivery is inevitable. However, in present times, mothers could request for C-section, even without any medical indications. And apparently, it becomes increasingly popular. It

\author{
Corresponding author: \\ dr. Levina Chandra Khoe, MPH \\ Department of Community Medicine \\ Medical Faculty, Universitas Indonesia \\ Email: levina.chandra01@ui.ac.id
}

was estimated that $21.1 \%$ of the world's births were occurred through C-section in 2015, increased almost double from $12.1 \%$ in $2000 .{ }^{1}$ The rate of Csection on maternal request is also growing. Analysis based on the WHO Global Survey on Maternal and Perinatal Health (2004-2008) identified the rate of C-section was $25.7 \%$, and about $1 \%$ of them were without medical indications. ${ }^{2}$ In Norway population-based study, $5 \%$ of the deliveries were occurred through elective Csection. ${ }^{3}$ Another study using Swedish Registry also identified a three-fold increase of $\mathrm{C}$-section on maternal request in 10-year period. ${ }^{4}$ Similar situation was found in Indonesia, where about 3.7\% of Caesarean deliveries in tertiary hospitals were by maternal request. ${ }^{5}$

Even though $\mathrm{C}$-section delivery is sometimes necessary and lifesaving, it can also bring negative consequences for mothers and infants. The short- 
term health risk includes post-partum infection, hemorrhage, venous thromboembolism, or even maternal death. ${ }^{6-8}$ There are also long-term risks for the mothers, child, and subsequent pregnancies. ${ }^{9}$ The World Health Organization (WHO) gave statement on C-section delivery rate and acknowledging that the effect of $\mathrm{C}$-section on pediatric outcomes are still unclear. ${ }^{10}$ Castillo-Ruiz reported an unexpected effect on neonatal brain development and behavior in mice delivered through $\mathrm{C}$-section. ${ }^{11}$ The rates of cell death in the brain were either unchanged or increased at $\mathrm{C}$-section delivery, contrary to vaginal delivered mice, which exhibited an abrupt, transient decrease in cell death. Some human studies also suggested the possible effect of Caesarean birth method on child's cognitive, emotions, and behaviour. ${ }^{12-13}$

Nevertheless, there is no doubt that we also found healthy children born through $\mathrm{C}$-section delivery. It is also important to note that various factors influenced children's growth and development, not merely the birth mode. Little is known about the effect of birth mode on child's neurodevelopment and cognitive behavior. This review aims to provide an overview on the available evidences, exploring how $\mathrm{C}$-section mode could affect brain development in short- and long-term.

\section{Methods}

We focus on the effects of C-section delivery mode on children's brain development, neurodevelopment, cognitive, and behavior. Studies on the effects of C-section on children's health, such as obesity, allergy, asthma, were excluded. We only included articles that were published in a peerreviewed scientific journal. Articles were identified from electronic database, i.e. PubMed, Cochrane, and Google Scholar. The searching strategies included terms related to Caesarean, brain development, neurodevelopment, behavior and emotional development. Articles were either in English or Indonesian language, and not limited to publication year.

\section{Results and Discussion}

\section{C-section delivery mode and brain development}

There are clearly differences between vaginal delivery and C-section delivery, but the question is how do these differences affect health outcomes in infants? Natural born infant experienced hormonal surge through labor process. Mother's body is naturally prepared for delivering infant, with increasing level of estrogen, oxytocin, prostaglandin activity, beta-endorphins, and prolactin receptors. The infant's body also experiences changes to be fully matured. Buckley ${ }^{14}$ noted some possible impacts of planned birth on the infant's brain, e.g. reduced brain maturity and brain-hormone. It is well understood that premature infant has higher risk for brain injury because of the lack of oxygen. About 5 to $10 \%$ of infants born before 32-weeks had significant brain impairment, e.g. cerebral palsy, and more than half developed cognitive or behavior disorders. ${ }^{15-18}$ Nevertheless, there still lack of evidence on how elective C-section delivery which commonly occurs between the gestation age of 37 to 39 weeks could have impact on the infant's brain. Clinical guidelines recommended C-section delivery on maternal request to be performed after 39 weeks due to risk of respiratory complications, however, no sufficient evidences related to risk of brain immaturity before the gestation age of 39 weeks. ${ }^{19}$

Neonates delivered through $\mathrm{C}$-section have lower concentration of stress hormone that may affect the hypothalamic-pituitary-adrenal (HPA) axis, which latter could have implications on neonatal cardiovascular and autonomic nervous system development. Castillo-Ruiz identified a surge in vasopressin among mice with vaginal delivery, and a relatively small increase among those delivered through $\mathrm{C}$-section. The concentration of circulating vasopressin is almost 100-fold higher in infants born by vaginal delivery compared to Csection. ${ }^{20}$ It is assumed that these high concentration of vasopressin acts as natural analgesia in infants born by vaginal delivery. The circulating levels of vasopressin is generally link with concentrations in the central nervous system, and it is reported to decrease neuronal apoptosis in cell culture.

Aside from hormonal effects, Deoni et $\mathrm{al}^{21}$ performed a cohort study towards two-week-old neonates, three-months to 5-year old, and 8-year old children to observe their brain structural and functional connectivity. The result indicated 
significant differences in the first three years, then it was gradually decreased and became unobservable beyond the age of three. The two-week-old infants born by vaginal delivery had higher $4-10 \%$ of mean fractional anisotropy, compared to those by $\mathrm{C}$ section. Infant at three-month-old born by vaginal delivery also had better myelination in the frontal, temporal, parietal, and occipital white matter, compared to those delivered by $\mathrm{C}$-section. Hence, the study found no significant differences brain structural connectivity between vaginal and Csection delivery in the older children ( 7.5 to 8.5 years old). There are possibility that breastfeeding and other environmental exposures, e.g. nutrition, sleep duration, screen-time, contribute to children neurodevelopment.

\section{C-section and its relation to behavior and emotional development}

There are theoretical assumptions that Caesarean delivery disrupts the normal change in infant's life and potentially cause traumatic experience that latter affect the child's psychology. The child might be prone to the issue of separation and abandonment. ${ }^{22}$ Nonetheless, these were all assumptions and not based on clinical evidence. Kelmanson et $\mathrm{al}^{12}$ did a case control study comparing 5-year old children born through $\mathrm{C}$-section on maternal request with those vaginal delivery. $\mathrm{He}$ found significant difference in terms of anxiety/depression, sleep problems, and internalizing problems. Another study by Huang et a ${ }^{23}$ confirmed these potential risk of emotional and behavioral problems among children born via C-section delivery. He compared children born through $\mathrm{C}$-section on maternal request, $\mathrm{C}$-section with medical indications, emergency $\mathrm{C}$-section, and vaginal delivery. Those delivered prior to 39-weeks on maternal request had the highest risk for emotional problems (RR: 3.48 ; 95\% CI: 1.68-7.22) and total difficult problems (RR: 2.17 ; 95\% CI: 1.18-4.02). Nevertheless, study by Rutayisire et $\mathrm{al}^{24}$ showed different result. He conducted a cross-sectional study among 8,900 preschoolers in China and found no significant association between emotional problems and mode of delivery (RR: 1.06; 95\% CI: 0.90-1.24).

In regards to its impact on cognitive and behavioral outcome, $\mathrm{C}$-section delivery could have been linked with the alteration of infant's gut microbiota which could affect the memory, mood, and cognition. ${ }^{25,26}$ It has been hypothesized that the central and enteric nervous system has bidirectional communications, known as gut-brain-axis. Different gut microbiota has been found in children born through $\mathrm{C}$-section compared with vaginal delivery, not only in the early life, but also beyond infancy. Study by Salminen et $\mathrm{al}^{27}$ found significantly higher Clostridium species in normally delivered children than Caesarean born. The study observed about 60 children aged 7 year old. Animal studies showed that gut microbial colonization affects brain development, particularly in stress reactivity, anxiety-like behavior ${ }^{28}$, and brain memory dysfunction. Possible mechanisms include changes in neurotransmitter and brain-derived neurotropic factors, modulation of enteric sensory afferents, and mucosal immune activation. ${ }^{29-32}$

Even though the direct causation between disturbed gut microbiota and child's behavioral development has not been established, there are assumptions that it influences children's cognitive disorder, such as autism spectrum disorders (ASD) and attention deficit hyperactivity disorder (ADHD). Study by Rutayisire et $\mathrm{al}^{24}$ found no differences in emotional problems, but significant result in behavioral problems, i.e. higher risk for total strength and difficulties questionnaire (OR: 1.27 ; 95\% CI: $1.10-1.46$ ) and pro-social behavior (OR: 1.27 ; 95\% CI:1.12-1.45). Another study by Mackay et $\mathrm{al}^{33}$ also found the risk of special education needs in children with Caesarean delivery. Specifically, he observed a dose-dependent relationship between risk of SEN with younger gestation age. Higher risk was found at preterm delivery i.e. the adjusted odds ratio for SEN at 3739 weeks was 1.16 (95\% CI: $1.12-1.20)$, at $33-36$ weeks was 1.53 (95\% CI: $1.43-1.63)$, at $28-32$ weeks was 2.66 (95\% CI: $2.38-2.97)$, and at $24-27$ weeks was 6.92 (95\% CI: 5.58-8.58). Nonetheless, the association between Caesarean delivery and behavioral disorders are still in debate. Curran et $\mathrm{al}^{34}$ analyzed a large cohort study in UK and found no association between planned C-section and ASD (aOR: 0.58 ; 95\% CI: $0.19-1.79$ ) or ADHD (aOR: $0.54,95 \%$ CI: $0.18-1.64)$. He also did a systematic review and calculated a pooled odds ratio of 1.23 (95\% CI: $1.07-1.40)$ for ASD and OR of 1.07 (95\% 
CI: 0.86--1.33) for ADHD. ${ }^{35} \mathrm{~A}$ recent systematic review on the association of $\mathrm{C}$-section with risk of neuro-developmental and psychiatric disorders also obtained similar result. ${ }^{36}$ The findings revealed a significant association with increased odds for ASD (OR: 1.33; 95\% CI: 1.24-1.41) and ADHD (OR: 1.17; 95\% CI: 1.07-1.26) among Caesarean infants. However, the study did not find significant association with depression, tic disorders or affective and non-affective psychoses. Even though the associations were significant, the numbers were relatively small, considering the prevalence of ASD was about $1 \%$ and ADHD was $7 \%$. In addition, the statistical heterogeneity was high, i.e. $\mathrm{I}^{2}=69.5 \%$ for ASD and $\mathrm{I}^{2}=79.2 \%$ for ADHD. Possible confounders, such as genetics, environmental factor, indication for $\mathrm{C}$-section may contribute to this heterogeneity. It is also importantly to consider future reviews and researches related to economic burden on specific child's neurodevelopment condition and its link with nutritional intervention. ${ }^{37,38}$ The role and knowledge of health care practitioners also point that need to be taking into consideration in order to keep the management of infants born with $\mathrm{C}$-section will get the proper nutritional intervention and management in the early life. The knowledge update in this particular subject is required. ${ }^{39,40}$

\section{Conclusion}

Our review found a growing body of evidences that support the association between C-section delivery and child's neurodevelopmental. The short-term effects were observed in the difference of brain development in the early life. Nevertheless, the long-term effects on child's emotional and behavioral problems were not yet conclusive. Future research should consider the genetic and environmental factors that could influence the emotional and behavioral development of a child. In addition, better understanding on how $\mathrm{C}$-section affects the gut-brain-axis and whether the effect would last in the long run should be explored.

\section{Conflict of Interest}

Authors declared no conflict of interest regarding this article.

\section{Open Access}

This article is distributed under the terms of the Creative Commons Attribution 4.0 International Licence

(http://creativecommons.org/licenses/by/4.0/), which permits unrestricted use, distribution, and reproduction in any medium, provided you give appropriate credit to the original author(s) and the source, provide a link to the Creative Commons license, and indicate if changes were made.

\section{Reference}

1. Boerma T, Ronsmans C, Melesse DY, Barros AJD, Barros FC, Juan L, et al. Global epidemiology of use of and disparities in caesarean sections. Lancet 2018;392:1341-8.

2. Souza JP, Gülmezoglu A, Lumbiganon P, et al. Caesarean section without medical indications is associated with an increased risk of adverse shortterm maternal outcomes: the 2004-2008 WHO Global Survey on Maternal and Perinatal Health. BMC Med 2010;8:71.

3. Størksen HT, Garthus-Niegel S, Adams SS, Vangen S, Eberhard-Gran M. Fear of childbirth and elective caesarean section: a population-based study. BMC Pregnancy Childbirth 2015;15:221.

4. Karlstrom A, Radestad I, Eriksson C, Rubertsson C, Nystedt A, Hildingsson I. Cesarean section without medical reason, 1997 to 2006: a Swedish register study. Birth 2010;37:11-20.

5. Festin MR, Laopaiboon M, Pattanittum P, Ewens MR, Henderson-Smart DJ, Crowther CA, and The SEA-ORCHID Study Group. Caesarean section in four South-East Asian countries: reasons for, rates, associated care practices and health outcomes. $B M C$ Pregnancy Childbirth 2009;9:17.

6. National Institute for Health and Clinical Excellence (2011) Caesarean Section (NICE Clinical Guideline 132). Available at: https://www.nice.org.uk/guidance/CG132 [Acces sed 8th May 2020].

7. Mascarello KC, Horta BL, Silveira MF. Maternal complications and cesarean section without indication: systematic review and meta-analysis. Rev Saude Publica 2017;51:105.

8. Blondon M, Casini A, Hoppe KK, Boehlen F, Righini M, Smith NL. Risks of venous thromboembolism after caesarean sections: a metaanalysis. CHEST 2016;50:572-96. 
9. Keag OE, Norman JE, Stock SJ. Long-term risks and benefits associated with cesarean delivery for mother, baby, and subsequent pregnancies: Systematic review and meta-analysis. PLoS medicine 2018;15: el002494. https://doi.org/10.1371/journal.pmed.1002494

10. WHO Statement on caesarean section rates. World Health Organization Human Reproduction Programme, 10 April 2015.Reprod Health Matters 2015 May; 23(45):149-50.

11. CastilloRA, Mosley M, Jacobs AJ, Hoffiz YC, Forg er NG. Birth delivery mode alters perinatal cell death in the mouse brain. Proc Natl Acad Sci USA 2018;115:11826-31.

12. Kelmanson IA. Emotional and behavioural features of preschool children born by Caesarean deliveries at maternal request. European Journal of Developmental Psychology 2013;10:6, 67690, DOI: $\underline{10.1080 / 17405629.2013 .787024}$

13. Adler SA, Wong-Kee-You AMB. Differential attentional responding in caesarean versus vaginally delivered infants. Atten Percept Psychophys. 2015;77:2529-39.

14. Buckley SJ. Executive Summary of Hormonal Physiology of Childbearing: Evidence and Implications for Women, Babies, and Maternity Care. $J$ Perinat Educ. 2015;24:145-53. doi:10.1891/1058-1243.24.3.145

15. Miller SP, Ferriero DM, Leonard C, Piecuch R, Glidden DV, Partridge JC, et al. Early brain injury in premature newborns detected with magnetic resonance imaging is associated with adverse early neurodevelopmental

Pediatr 2005;147:609-616.

16. Marlow N, Wolke D, Bracewell MA, Samara M. Neurologic and developmental disability at six years of age after extremely preterm birth. $N$ Engl $J$ Med 2005;352:9-19.

17. Walsh MC, Hibbs AM, Martin CR, Cnaan A, Keller RL, Vittinghoff E, et al. Two-year neurodevelopmental outcomes of ventilated preterm infants treated with inhaled nitric oxide. $J$ Pediatr 2010;156:556-561

18. Back SA, Miller SP. Brain injury in premature neonates: A primary cerebral dysmaturation disorder? Ann Neurol 2014;75:469-86.

19. NICE Clinical Guideline. Caesarean Section. National Institute of Clinical Excellence April 2004 (http://guidance.nice.org.uk/ CG13/Guidance/pdf/English)

20. Wellmann S, Bührer C. Who plays the strings in newborn analgesia at birth, vasopressin or oxytocin? Front Neurosci 2012;6:78. doi:10.3389/fnins.2012.00078
21. Deoni SC, Adams SH, Li X, et al. Cesarean Delivery Impacts Infant Brain Development. $A m \quad J$ Neuroradiol. 2019;40:169-77.

22. Verny TR, Weintraub P. Tomorrow's baby: The art and science of parenting from conception through infancy. 2002. New York, NY: Simon \& Schuster

23. Huang K, Yan S, Wu X, Zhu P, Tao F. Elective caesarean section on maternal request prior to 39 gestational weeks and childhood psychopathology: a birth cohort study in China. BMC Psychiatry 2019;19(1):22.

24. Rutayisire E, Wu X, Huang K, Tao S, Chen Y, Tao F. Childhood emotional and behavior problems and their associations with cesarean delivery. Rev. Bras. Psiquiatr. [Internet]. 2018 June [cited 2020 June 15] ; 40( 2 ): 145-153. Available from:

http://www.scielo.br/scielo.php?script=sci_arttext\& pid $=$ S1516-

44462018000200145\&lng=en. $\quad$ Epub Oct 02, 2017. http://dx.doi.org/10.1590/1516-4446-20162152.

25. Galland L. The gut microbiome and the brain. $J \mathrm{Med}$ Food. 2014;17(12):1261-1272.

26. Cryan JF, Dinan TG. Mind-altering microorganisms: the impact of the gut microbiota on brain and behaviour. Nature Reviews Neuroscience 2012; 13:701-12.

27. Salminen S, Gibson GR, McCartney AL, Isolauri E. Influence of mode of delivery on gut microbiota composition in seven year old children. Gut 2004;53:1388-9.

28. Diaz Heijtz R, Wang S, Anuar F, et al. Normal gut microbiota modulates brain development and behavior. Proc Natl Acad Sci USA 2011;108:304752.

29. Marilia Carabotti, Annunziata Scirocco, Carola Severi, Carola Severi. The gut-brain axis: interactions between enteric microbiota, central and enteric nervous systems. Ann Gastroenterol 2015;28:203-209.

30. Diaz Heijtz R, Wang S, Anuar F, Qian Y, Björkholm B, Samuelsson A, et al. Normal gut microbiota modulates brain development and behavior. Proc Natl Acad Sci USA 2011; 108:3047-52.

31. Gareau MG, Wine E, Rodrigues DM, Cho JH, Whary MT, Philpott DJ, et al. Bacterial infection causes stress-induced memory dysfunction in mice. Gut 2011 Mar; 60:307-17.

32. Kunze WA, Mao YK, Wang B, Huizinga JD, Ma X, Forsythe $\mathrm{P}$, Bienenstock J. Lactobacillus reuteri enhances excitability of colonic AH neurons by inhibiting calcium-dependent potassium channel opening. J Cell Mol Med 2009; 13:2261-70. 
33. MacKay DF, Smith GCS, Dobbie R, Pell JP. Gestational Age at Delivery and Special Educational Need: Retrospective Cohort Study of 407,503 Schoolchildren. PLoS Med 2010;7: e1000289.

34. Curran EA, Cryan JF, Kenny LC, Dinan TG, Kearney PM, Khashan AS. Obstetrical mode of delivery and childhood behavior and psychological development in a British cohort. J Autism Dev Disord 2016;46:603-14.

35. Curran EA, O'Neill SM, Cryan JF, Kenny LC, Dinan TG, Khashan AS, Kearney PM. Research review: Birth by caesarean section and development of autism spectrum disorder and attentiondeficit/hyperactivity disorder: a systematic review and meta-analysis. J Child Psychol Psychiatry 2015; 56:500-8.

36. Zhang T, Sidorchuk A, Sevilla-Cermeño L, et al. Association of Cesarean Delivery with Risk of Neurodevelopmental and Psychiatric Disorders in the Offspring: A Systematic Review and Metaanalysis. JAMA New Open. 2019;2:e1910236.
37. Botteman MF, Munasir Z, Sulistomo AW, Horodniceanu EG, Bhanegaonkar AJ, Ji X, et al. Economic value of atopic dermatitis prevention via partially-hydrolyzed whey-based infant formula (PHF-W) use in high-risk, non-exclusively breastfed, Indonesian urban infants: results of a costeffectiveness model. World Nut J. 2019;2(2):43-55

38. Lamsal R, Zwicker JD. Economic evaluation of interventions for children with neurodevelopmental disorders: opportunities and challenges. Appl Health Econ Health Policy. 2017;15(6): 763-72

39. Bardosono S, Hildayani R, Chandra DN, Basrowi RW, Wibowo Y. The knowledge retention after continuing health education among midwives in Indonesia. Med $J$ Indones [Internet]. 2018Sep.9 [cited 2020Aug.7];27(2):128-33.

40. Ahmed M, Pai B, Reynolds T. Retention of knowledge of the Paediatric Life Support guidelines. J Coll Physicians Surg Pak. 2012;22(3):194-5. 